\title{
Interação entre Irmãos: Deficiência Mental, Idade e Apoio Social da Família
}

\author{
Siblings' Interaction: Mental disability, Age and Family Social Support
}

\author{
Célia Cristina Nunes ${ }^{*} a$ \& Ana Lúcia Rossito Aiello*b \\ ${ }^{a}$ Universidade de São Paulo, Ribeirão Preto, Brasil \\ ${ }^{b}$ Universidade Federal de São Carlos, São Carlos, Brasil
}

\begin{abstract}
Resumo
Os objetivos deste estudo foram: (a) caracterizar a interação entre díades de irmãos, divididas em dois grupos - G1, com o irmão deficiente mental pré-adolescente, e G2, com esse irmão adulto; (b) comparar os desempenhos dos grupos nas interações; e (c) avaliar diferenças entre os grupos nas interações, considerando o apoio social da família. Foram realizadas sessões de observação de interações, e aplicação de instrumentos de auto-relato; os cuidadores responderam escalas para avaliação do apoio social. Os resultados sugeriram diferença no comportamento de ajudante do irmão com desenvolvimento típico, com taxa de ocorrência maior para G1. Nas escalas, houve diferença estatisticamente significativa na Escala de Apoio à Maternidade/Paternidade, revelando-se menor apoio para G1. Especula-se que, como as famílias do G1 recebem menor apoio deste nível, há maior demanda de ajuda requerida pelo filho deficiente, que pode ser suprida pelos irmãos menores com desenvolvimento típico, que desempenham o papel de ajudante em maior escala que os adultos.

Palavras-chave: Interação entre irmãos; deficiência mental; apoio social; observação.
\end{abstract}

\begin{abstract}
The purpose of the present study was: (a) To describe the relationship in sibling's dyads, separated in two groups - G1, with pre-adolescent mentally retarded sibling, and G2, with this adult sibling; (b) To compare the performance of both groups in the interactions; and (3) To evaluate differences in the relationships between the groups when family social support is taken into account. Sessions of sibling's interactions were videotaped, and self-report instruments were used. The caretakers answered scales of social support. Results suggested differences concerning the behavior of the helper of the sibling with characteristic development, with highest occurrence in G1. Scales' results indicated statistically significant difference for the Parenting Support from Family/Friends Scale, showing less support for G1. It is possible to suggest that because families from G1 have less support from this level from families and friends, a bigger demand of help is required from the disabled member, which can be compensated by the young siblings with typical development, who perform the helper's role in greater level than the adults.

Keywords: Sibling relationships; mental disability; social support; observation.
\end{abstract}

O desenvolvimento infantil é influenciado por vários fatores, dentre os quais estão os relacionamentos que ocorrem no contexto familiar das crianças. Nesse âmbito, há um crescente reconhecimento de que a criança relacionase na família com outros agentes sociais além da mãe, como pai, avós e irmãos. Isso é evidenciado, sobretudo, quando o sistema familiar é analisado a partir da perspectiva sistêmica, segundo a qual a família é entendida como um sistema interacional, constituído pelos subsistemas conjugal, parental, fraterno e extra-familiar (Turnbull \&

\footnotetext{
"Endereço para correspondência: USP-FFCLRP, Avenida Bandeirantes, 3900, Bloco 3, Bairro Monte Alegre, 14040901, Ribeirão Preto, SP. E-mail:nunes_celia@yahoo.com.br Apoio financeiro da Coordenação de Aperfeiçoamento de Pessoal de Nível Superior (CAPES).

"Endereço para correspondência: Universidade Federal de São Carlos, Departamento de Psicologia, Rodovia Washington Luís, km 235, São Carlos, SP, 13565-905. E-mail: ana.aiello@terra.com.br
}

Turnbull, 2001). Especialmente a relação estabelecida no subsistema fraterno é essencial, não apenas no início da vida, mas também durante a adultez, dado que o relacionamento entre irmãos é o mais duradouro dos relacionamentos familiares (Frank, 2000; Lobato, 1990).

Os irmãos são importantes fontes de apoio, companheirismo, cooperativismo e ajuda uns para os outros, ainda que o relacionamento fraterno possa, ao mesmo tempo, caracterizar-se pelo conflito, competição e até mesmo agressão (Dunn, 1983; Turnbull \& Turnbull, 2001). Lobato (1990) afirma que nas interações entre crianças, sobretudo entre irmãos, há maior similaridade de papéis, o que pode conduzir a conflitos, assim como à resolução deles, ao contrário do que ocorre nas interações adulto-criança (como no subsistema parental), nas quais o adulto tem vantagem de poder. Logo, algumas das primeiras noções sobre divisão de materiais, competição, rivalidade, e compromisso são aprendidas durante as negociações com os irmãos. 
Apesar do conhecimento produzido nos estudos citados anteriormente, as características do relacionamento entre irmãos ainda são confusas e incertas (Cuskelly, 1999), como será descrito adiante. Também, quando são consideradas as particularidades das famílias, torna-se mais complexa a análise desse relacionamento. Uma dessas particularidades envolvidas nas famílias, como fator de influência sobre a ligação entre os irmãos, é a presença de um membro com necessidades especiais.

Ao analisar-se a família de uma perspectiva sistêmica, a presença de uma criança com necessidades especiais afeta não somente os pais, como também os outros membros e, especialmente, os irmãos, que podem se envolver direta ou indiretamente nos cuidados com a criança com necessidades especiais (Hallahan \& Kauffman, 2000). Entretanto, sabe-se pouco acerca dos irmãos de indivíduos deficientes, sobretudo no Brasil, onde essa é ainda uma área pouco explorada em termos de pesquisa se comparada a países como EUA e Canadá. Ao apresentarem os índices sobre as produções científicas nacional e estrangeira acerca de crianças com deficiência mental e suas famílias, PereiraSilva e Dessen (2001) indicam que as relações mais estudadas no contexto familiar são aquelas entre mãe e criança (39\%), quando comparadas as outras interações como pai-criança e criança-irmão.

Nesse ínterim, sabe-se que os irmãos de pessoas com necessidades especiais freqüentemente passam pelas mesmas experiências (medo, raiva, culpa, etc.) que os pais (Gargiulo, 2003). Na realidade, os irmãos podem encontrar maior dificuldade do que os pais para enfrentar tais sentimentos, especialmente quanto menor for a idade dos irmãos e mais restritas forem as informações recebidas acerca da deficiência do membro da família. Contudo, a literatura na área de investigação sobre irmãos de indivíduos com necessidades especiais é ainda confusa e inconsistente (Cuskelly, 1999), conforme citado anteriormente. Hallahan e Kauffman (2000), por exemplo, demonstram que os relacionamentos entre irmãos nos quais há uma pessoa com necessidades especiais podem gerar no irmão com desenvolvimento típico tanto maior tolerância em relação aos outros, maior compaixão e altos níveis de empatia e altruísmo, quanto depressão, retraimento social, baixa auto-estima e pobre relacionamento interpessoal.

Glasberg (2000), por exemplo, ao citar dados da literatura afirma que irmãos de crianças com autismo podem expressar visões mais negativas acerca do relacionamento com seus irmãos, relatar mais problemas com os comportamentos inadequados dos irmãos, ser mais preocupados com o futuro dos irmãos, brincar menos com eles, sentir-se mais sozinhos e ter menos amigos do que os irmãos de crianças com deficiência mental ou irmãos de crianças sem deficiência. Por outro lado, Van Riper (2000), investigando variáveis familiares associadas ao bem-estar de irmãos de crianças com síndrome de Down, encontrou que, segundo relato da mãe, os participantes eram socialmente competentes, com baixa incidência de problemas de comportamento.

Adicionalmente, alguns estudos não encontraram diferenças quando compararam irmãos de indivíduos com desenvolvimento típico aos irmãos de pessoas com necessidades especiais. Isso foi demonstrado, por exemplo, no estudo de Gamble e McHale (1989), que examinaram o estresse e enfrentamento de irmãos de crianças deficientes e irmãos de crianças com desenvolvimento típico. Neste estudo, o estresse vivenciado pelos irmãos era indicado em termos de sete categorias de eventos estressores, que se referiam a situações envolvendo o irmão com necessidades especiais (algo que ele fez ou que tenha acontecido com ele, por exemplo). Em tal estudo, não houve diferenças entre os dois grupos de irmãos quanto à freqüência de estressores.

Contudo, como é possível notar pela análise dos estudos anteriormente apresentados, as pesquisas em sua maioria, têm se preocupado mais em investigar aspectos do ajustamento (competência social, estresse e enfrentamento, etc.) dos irmãos, em detrimento de trabalhos que busquem identificar a natureza das interações entre crianças ou adultos com necessidades especiais e seus irmãos. Além disso, dentre os trabalhos que se preocuparam em analisar as interações fraternas, a maioria deles empregou na coleta de dados instrumentos de relato de pais ou outros informantes e, em número menor, auto-relato dos irmãos (Hastings, 2003). Alguns autores (Cuskelly, 1999; Rossiter \& Sharpe, 2001) defendem que a utilização de mais de um tipo de coleta de dados, como o auto-relato ou relato de outros, e observações permitem obter dados que se complementam, concedendo, assim, maior rigor ao procedimento de coleta de dados, acarretando maior índice de fidedignidade dos resultados.

Lobato (1990) resumiu os estudos observacionais realizados por Stoneman, Brody, Davis e Crapps e publicados em 1987, 1988 e 1989, nos quais foram utilizados dados complementares de entrevistas de auto-relato dos irmãos e relato dos pais. Nesses estudos, foram filmadas crianças com deficiência mental e com desenvolvimento típico (quatro a oito anos) em situações de interação com seus irmãos mais velhos (seis a 12 anos). Os resultados indicaram que não houve diferenças em relação a aspectos emocionais das interações entre os dois grupos de irmãos, e a taxa de afeição ou de agressividade expressas pelas crianças também não diferiu. Entretanto, quando comparados às díades de irmãos sem necessidades especiais, os irmãos das crianças com deficiência mental assumiram mais prontamente o papel de líder ou cuidador do irmão, sendo esta interação caracterizada por assimetrias de papéis. A assimetria de papéis significa que o irmão com desenvolvimento típico assume o papel da criança mais velha e a criança com necessidades especiais assume o papel da mais jovem, independentemente das idades cronológicas de ambas (Orsmond \& Seltzer, 2000). O resultado das entrevistas com as crianças e com os pais indicaram que quanto 
maiores forem as responsabilidades assumidas na família pelo irmão, menor é sua participação em atividades fora de casa, e maior é o nível de conflito notado em seu relacionamento com a criança deficiente mental.

Os resultados de Nunes e Aiello (2004) foram na mesma direção daqueles citados anteriormente. Este trabalho também se interessou por investigar as características das interações entre uma díade de irmãs, na qual um dos membros era uma criança com síndrome de Down, em relação a uma díade com duas irmãs com desenvolvimento típico. Foram empregados instrumentos de auto-relato e observações diretas de situações estruturadas de interação. Assim, verificou-se que a irmã da criança com síndrome de Down era quase sempre líder nas atividades de interação, enquanto que a irmã da outra díade assumia pouco este papel. No entanto, pelo fato de se tratar de um estudo de caso, as autoras apontam para a necessidade de estudos que envolvam mais participantes, permitindo a possível generalização dos resultados obtidos.

Além do mais, são vários os fatores que delineiam a forma como os irmãos respondem à presença de um indivíduo com necessidades especiais na família, dentre os quais a idade dos irmãos, e a disponibilidade de apoio social da família (Frank, 2000; Hallahan \& Kauffman, 2000; Hastings, 2003).

\section{Apoio Social}

Turnbull e Turnbull (2001) afirmam que o apoio social pode proporcionar melhorias na satisfação conjugal e nas relações entre pais e filhos. Nesse sentido, o apoio social pode exercer um efeito indireto sobre o relacionamento entre irmãos, dado que este relacionamento influencia e é influenciado pelas relações dos subsistemas conjugal e parental. Hastings (2003) indica que alguns estudos têm sugerido que o apoio social disponível às famílias pode afetar o ajustamento dos irmãos, e, também, que o apoio social percebido pelos pais tem sido associado ao ajustamento de irmãos em famílias de crianças com transtornos de desenvolvimento e outras deficiências.

Entretanto, é impor tante ressal tar que há um vasto campo de discussão na literatura tratando da questão do que é o apoio social (Langford, Bowsher, Maloney, \& Lillis, 1997) e seu impacto sobre as relações familiares. No presente trabalho, a definição de apoio social empregada é a de Dunst, Trivette e Cross (1986), e refere-se à assistência fornecida por outras pessoas e/ou grupos às crianças e às famílias (assistência emocional, psicológica, física, informacional, instrumental, e material), e que direta ou indiretamente influencia o comportamento do receptor de tal ajuda. Em termos de recursos, a definição utilizada é a indicada por Leet e Dunst (1994), e refere-se a recursos físicos e humanos, incluindo alimento, abrigo, recursos financeiros, transporte, tempo para estar com a família e os amigos, e cuidados com a saúde.

Hastings (2003), por exemplo, utilizando-se da definição de Dunst et al. (1986), examinou o papel do apoio social disponível às famílias de crianças autistas (quatro a 16 anos), e como este apoio poderia afetar os irmãos, considerando-se também a severidade da deficiência da criança. As mães de 78 crianças autistas apontaram o apoio social percebido, respondendo a Escala de Apoio da Família (Dunst, Jenkins \& Trivette, 1994), e os indicadores de ajustamento (problemas emocionais e de conduta, hiperatividade, problemas com os pares) dos irmãos com desenvolvimento típico, com média de idade de 6,7 anos. Os resultados revelaram que o apoio social funcionou como moderador do impacto da severidade do autismo sobre o irmão. Adicionalmente, os irmãos de famílias de crianças com autismo menos severo apresentaram menores problemas de ajustamento quando estava disponível maior apoio social à família.

\section{Idade dos Irmãos}

Frank (2000), afirma que os papéis assumidos pelos irmãos, em termos de companheirismo, suporte e aprendizagem social, variam ao longo dos anos e, por isso, tanto os benefícios como as influências sobre o relacionamento também sofrem mudanças. Com o decorrer dos anos o relacionamento entre os irmãos vai reforçando o companheirismo, à medida que os irmãos despendem mais tempo juntos. Durante a adolescência, uma ambivalência passa a caracterizar esta relação, pois cada um busca um senso de identidade que é internamente congruente e consistente com os valores familiares e com a rede de ligações externas. Quando adultos, os irmãos mantêm um relacionamento mais igualitário.

Dyson (1989), por exemplo, encontrou que irmãos mais novos de crianças com distúrbios de desenvolvimento apresentavam maiores níveis de problemas de ajustamento. Sobre as pesquisas com irmãos adultos de indivíduos com necessidades especiais há poucas investigações desse tipo, e, portanto, pouco se sabe sobre tal relacionamento (Orsmond \& Seltzer, 2000). Na meta-análise realizada por Rossiter e Sharpe (2001), foram encontradas diferenças significativas entre crianças e adultos irmãos de pessoas com deficiência mental. Embora haja poucos estudos sobre irmãos adultos, estes autores afirmam que parece ocorrer um ajustamento psicológico mais positivo em adultos, em termos de comportamentos internalizantes e externalizantes, competência social, depressão e ansiedade, pelo fato de haver na adultez uma diminuição do impacto do irmão deficiente. Possivelmente isso ocorre devido ao desenvolvimento cognitivo e social nessa fase, estar em estágio mais avançado, o que conduziria a mecanismos adequados de enfrentamento.

Em vista do que foi exposto, os objetivos do presente trabalho foram: (a) caracterizar a interação entre díades de irmãos, divididas em dois grupos - um com o irmão deficiente mental com idade entre 10 e 14 anos (Grupo 1) e outro grupo com idade entre 21 e 24 anos (Grupo 2); (b) comparar os desempenhos nas interações dos dois grupos; e (c) avaliar se há diferenças nos grupos na interação dos irmãos, quando se considera o nível de apoio social da família, bem como a adequação de recursos disponíveis a ela. 
As hipóteses desta investigação eram: (a) as interações entre díades de irmãos em idade adulta seriam mais positivas, e as interações entre os irmãos mais jovens seriam caracterizadas por maior ajuda por parte dos irmãos ou irmãs com desenvolvimento típico em direção ao irmão com necessidades especiais; e (b) se houvesse diferenças entre os grupos no nível de apoio social indicado pelos cuidadores, as interações entre os irmãos do grupo com maior apoio seriam mais positivas, com maior ocorrência das categorias de comportamento professor, ajudante, companheiro de brincadeira, e ação positiva, e menor ocorrência das categorias ação negativa e ausência de interação. Tais categorias de comportamento foram elencadas a partir do estudo de Nunes e Aiello (2004), e descrevem comportamentos que ocorrem tipicamente em situações de interação entre irmãos.

\section{Método}

\section{Participantes}

Participaram deste estudo oito famílias de díades de irmãos, nas quais o irmão mais velho fosse deficiente mental (leve a moderado). As famílias foram divididas em dois grupos: Grupo 1 (G1), em que o irmão com necessidades especiais tinha entre 10 e 14 anos, e o Grupo 2 (G2), em que o irmão com necessidades especiais tinha entre $21 \mathrm{e}$ 24 anos. Os critérios de participação foram: (a) o irmão sem necessidades especiais deveria ser mais jovem do que o participante deficiente mental, com diferença de idade entre os dois irmãos de até cinco anos, e (b) os dois irmãos alvos do estudo deveriam viver na mesma residência. Além dos irmãos, participaram os cuidadores, que forneceram informações sobre o nível de apoio social da família. As famílias participantes foram identificadas em uma instituição de atendimento a crianças e jovens com necessidades especiais, no interior de São Paulo. O G1 era constituído por participantes com maiores prejuízos em termos de linguagem, desenvolvimento motor, e, conseqüentemente, atividades de vida diária (AVDs), dado que três irmãos deste grupo apresentavam maior nível de dependência de outras pessoas nestas áreas. O nível sócio-econômico de mais da metade das famílias $(n=5)$ era baixo (Classe $\mathrm{C}-$ Critério Brasil, Instituto Brasileiro de Geografia e Estatística [IBGE]), mas variou entre as classes B2 e E.

\section{Instrumentos, Local e Materiais}

Os instrumentos empregados foram:

1.Escala de Apoio da Família ([Family Support Scale] - Dunst et al., 1994), composta por 18 itens, com medidas de auto-relato designadas a avaliar em que grau recursos potenciais de apoio têm sido úteis, isto é, suportivos às famílias, em termos de cuidado e educação dos filhos. Tais recursos potenciais de apoio referem-se a indivíduos (marido/esposa, pais, amigos, profissionais) e grupos (igreja, escola). O cuidador é solicitado a indicar o quão colaborador cada uma das pessoas ou grupo de pessoas citadas nos itens tem sido para ele em termos de educação e cuidados para os filhos, no período dos últimos 6 meses. A classificação é indicada numa escala do tipo Likert de 5 pontos (nunca colabora a colabora extremamente). Se alguma das fontes de apoio indicada não estiver disponível para a família durante o referido período, a resposta sugerida deve ser não disponível (ND). A escala em sua versão original tem consistência interna de 0.79 entre os 18 itens e 0.77 entre a correlação média dos 18 itens e dos itens totais (Dunst et al., 1994). Para a análise dos dados calcula-se o escore total da escala somando-se os pontos, sendo que pontuações mais altas indicam maior nível de apoio da família. O escore total mínimo é 18 e o máximo 90.

2.Escala de Recursos da Família ([Family Resource Scale] - Leet \& Dunst, 1994), constituída de 29 itens, que medem a adequação de recursos que têm sido identificados como principais componentes do suporte intra e extra-familiar. O cuidador deve indicar o quanto cada um dos recursos citados nos itens estão adequados para atender as necessidades da família, dentro de um mês. A classificação é feita numa escala do tipo Likert de 5 pontos (nunca adequado a sempre adequado). Para aqueles itens que não se aplicam àquela família, indica-se a resposta não se aplica (NA). A escala em sua versão original tem consistência interna de 0.92 entre os itens e 0.97 entre a correlação média dos itens e os itens totais (Leet \& Dunst, 1994). Para a análise dos dados são somados os pontos indicados para cada item, constituindo o escore total, sendo que pontuações mais elevadas indicam maiores níveis de adequação dos recursos. O escore total mínimo é 29 e o máximo 145.

3.Escala de Apoio de Familiares e Amigos à Maternidade/Paternidade ([Parenting Support from Family and Friends] - Bonds, Gondoli, Sturge-Apple, \& Salem, 2002), com 38 itens, divididos em quatro subescalas: apoio prático (envolve a ajuda prática, como conseguir dinheiro emprestado ou ajuda em tarefas domésticas); apoio informacional (envolve a ajuda na resolução de problemas, como receber um bom conselho sobre um problema); apoio a estima (envolve o sentimento de ser valorizado pelos outros); e apoio para desabafos (ter alguém com quem desabafar). Os itens avaliam o apoio à maternidade/paternidade que o cuidador recebe de familiares (não incluindo o cônjuge) e amigos. É uma escala do tipo Likert, de 4 pontos (discorda com certeza a concorda com certeza). A consistência interna da escala em sua versão original é de 0,94 entre a correlação média entre os 38 itens e os itens totais (Bonds et al., 2002). Cada subescala possui um escore parcial, e a soma destes indica o escore total, sendo que escores maiores revelam maiores níveis de apoio. O escore total mínimo é 38 e o máximo 152.

As três últimas escalas citadas foram submetidas a um processo de validação aparente por Nunes (2006). 
4.Entrevista com Irmãos de Indivíduos com Necessidades Especiais (Nunes \& Aiello, 2004) - composta por perguntas abertas, subdivididas em seis grupos: constatação e implicações da deficiência, relacionamento, aceitação social, assimetria e responsabilidade, e experiência de vida e afetividade.

5.Formulário de Irmãos (Nunes \& Aiello, 2004) - engloba 20 itens semi-estruturados que se referem a situações de interação entre os irmãos, nas quais o irmão com desenvolvimento típico pode assumir uma dentre seis categorias de comportamentos dirigidos ao irmão com necessidades especiais: professor - o irmão explica, modela, demonstra ou questiona com a proposta de ensinar algum novo princípio, conceito ou fato; líder - o irmão lidera ou solicita (verbal ou não-verbalmente) o desempenho ou não de um certo comportamento, e quando o irmão declara seus próprios direitos, tentando influenciar o compor tamento do outro; ajudante - o irmão apresenta qualquer tentativa de oferecer assistência física ou ajuda ao outro; ação positiva - o irmão beija, abraça ou dá demonstrações afetivas ao outro, e quando ele sorri, elogia ou expressa entusiasmo verbal para o irmão; ação negativa - o irmão agride, briga, insulta ou apresenta expressões faciais negativas para o irmão; companheiro de brincadeira - o irmão pede opinião ao outro sobre a atividade na qual estão engajados, ou o irmão engajase em jogos com o outro envolvendo objetos e brinquedos. $O$ irmão deve classificar a freqüência de ocorrência de tais eventos numa escala de 5 pontos do tipo Likert (sempre a nunca).

Adicionalmente, foram realizadas sessões de observação de situações de interação entre os irmãos. A análise de tais sessões envolveu o registro das mesmas categorias de comportamento descritas no Formulário de Irmãos (professor, líder, ajudante, ação positiva, ação negativa, companheiro de brincadeira), além da categoria ausência de interação (quando, embora os irmão estejam engajados na mesma atividade, o irmão sem necessidades especiais não olha para o outro, nem se dirige física ou verbalmente ao outro).

Foram utilizados também o Questionário de Avaliação Sócio-Econômica do IBGE $^{1}$ e a Entrevista Inicial (Williams \& Aiello, 2001), para a caracterização dos participantes, e o diário de campo, onde foram registradas as atividades e condições de cada encontro, bem como comentários sobre fatos relevantes ocorridos durante o trabalho, que pudessem ser úteis na análise dos dados.

Os encontros com os cuidadores e com os filhos aconteceram na residência dos participantes, com prévio agendamento e autorizações. Como materiais foram utilizados: mini-gravador e microfitas cassete para gravação das entrevistas com os irmãos, câmera filmadora e fitas

${ }^{1}$ Retirado de http://www.ibope.org.br de vídeo, para a filmagem das sessões, TV e videocassete para a análise das filmagens, e folhas de registro, com as categorias de comportamentos (professor, líder, ajudante, companheiro de brincadeira, ação positiva, ação negativa e ausência de interação) a serem analisadas. Também utilizou-se jogo de dominó (tradicional e de figuras), CDs e rádio, brinque-dos e materiais diversos para as atividades de observação.

\section{Procedimento}

Inicialmente os cuidadores responderam os instrumentos sobre dados da família, situação sócio-econômica e nível de apoio social, e posteriormente os irmãos sem deficiência mental responderam o Formulário e a Entrevista de Irmãos. Findada esta fase de coleta dos dados, passouse a fase de observação das situações de interação entre os irmãos. Tais situações foram propostas pela pesquisadora, e as filmagens das mesmas também foram previamente autorizadas pelos responsáveis e pelos irmãos maiores de idade. Cada díade de irmãos foi submetida a três sessões de observação: jogo de dominó, escolha de CDs e de músicas para ouvirem juntos, e atividade de hábito dos irmãos selecionada a partir do relato apresentado pelo irmão sem necessidades especiais na entrevista. Não houve um tempo fixo estabelecido para as sessões de observação, dado que isso dependeu do envolvimento de cada díade, bem como da natureza da atividade a ser desempenhada. Foram realizadas 24 sessões de observação, perfazendo um total de 345'18" de gravação, variando de 4'20" a 48'10". A fase final consistiu do desligamento das famílias, com entrega de uma apostila com informações sobre a dinâmica de famílias de crianças e jovens com necessidades especiais e sobre a relação fraterna. Além disso, foram concedidas orientações e encaminhamentos às famílias.

\section{Resultados}

\section{Entrevista com Irmãos}

Os resultados demonstraram, no tópico de constatação e implicações da deficiência, que os participantes do G1 souberam da deficiência do irmão por informações da mãe, e a maioria $(n=3)$ do G2 descobriram com o tempo. Entretanto, pode-se especular em relação a estes resultados que, dado o fato dos irmãos do G2 serem mais velhos (18 a 20 anos), seja possível que eles não se lembrem com exatidão como foi o processo de conhecimento acerca da deficiência do irmão. Além disso, os participantes de ambos os grupos $(n=8)$ afirmaram que não sabiam nada sobre a necessidade especial do irmão.

No tópico sobre aceitação social, todos os participantes $(n=8)$ relataram não sentir dificuldade em dizer aos amigos que tem um irmão ou uma irmã com necessidades especiais. Ademais, a maioria do G1 $(n=3)$ e todos do G2 $(n=4)$ afirmaram receber amigos em casa, sem destacarem problemas relacionados a isso.

Sobre assimetria e responsabilidade os resultados mostraram que os irmãos não sentem que os pais tratam dife- 
rencialmente os filhos; todos $(n=4)$ os irmãos do G2 confirmaram esse dado, e quase todos $(n=3)$ do G1 também o fizeram. Outro dado concernente a este tópico refere-se ao julgamento dos participantes de que o irmão enfrentará dificuldades no futuro; responderam afirmativamente a esta questão apenas uma irmã do G1, e três no G2.

Acerca do relacionamento, nenhum irmão do G1 relatou que o relacionamento fraterno é difícil, mas a maioria deles $(n=3)$ apresentou como maiores queixas deste relacionamento comportamentos dos irmãos ou irmãs considerados agressivos (beliscão, tapas). Já no G2, a maioria dos participantes $(n=3)$ afirmaram que o relacionamento com o irmão é difícil ou complicado, sendo, inclusive, enfáticos ao relatarem. Em relação à ajuda dispensada pelos participantes aos afazeres de cuidado com o irmão, no G1 todos os participantes $(n=4)$ relataram que ajudam, e no G2 apenas um.

\section{Formulário de Irmãos}

$\mathrm{Na}$ Figura 1 estão os resultados do Formulário para cada díade de irmãos, nos dois grupos. Considerando que escores maiores indicam relacionamentos mais positivos, os resultados apontam que as díades (D) com menores índices de relacionamento foram D1 e D7, que são constituídas por irmãos de mesmo gênero, ou seja, irmão - irmão. Tais resultados parecem ir na mesma direção daqueles de Orsmond e Seltzer (2000), os quais indicaram que díades do tipo irmãs-irmãs eram caracterizadas por maior cuidado e companheirismo, com maiores níveis de afetos positivos, quando comparados às díades irmãos-irmãos e aos irmãos de indivíduos sem necessidades especiais.

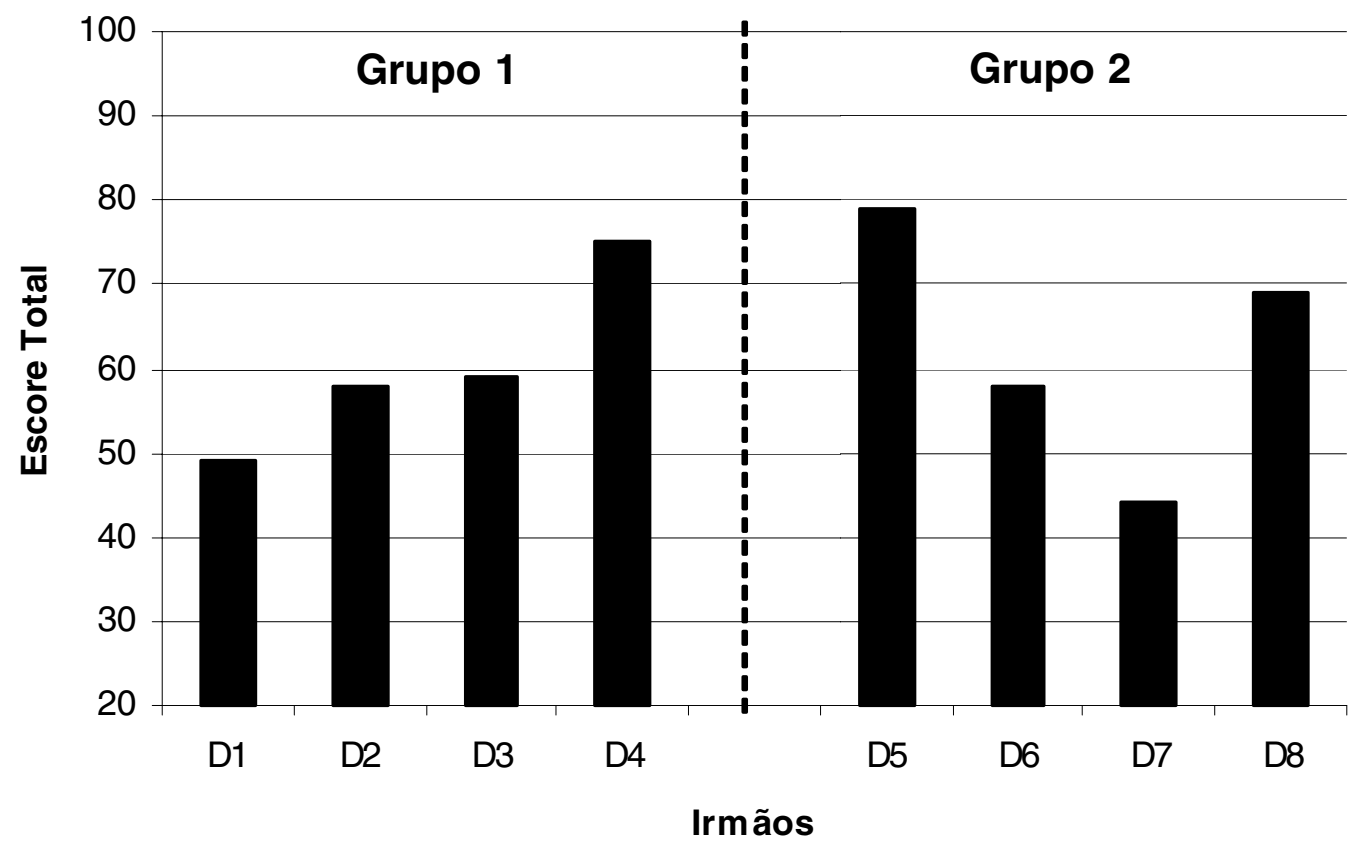

Figura 1. Resultados do Formulário, para os irmãos de cada díade, do G1 e do G2.

\section{Observações}

As análises das observações foram realizadas calculando-se a taxa de ocorrência de cada categoria de comportamento descritas anteriormente (professor, líder, companheiro, ajudante, ação positiva, ação negativa e ausência de interação) por oportunidade, utilizando-se intervalos de 10 segundos. Para garantir a fidedignidade dos registros, $25 \%$ das sessões foram analisadas por um segundo observador treinado. A média do índice de concordância obtida foi de $85,9 \%$, variando de $74,4 \%$ a $96,4 \%$.

A partir da análise da média total das taxas de ocorrência de cada categoria de comportamento, ao longo das três sessões, para G1 e G2 (Figuras 2 e 3), os resultados sugerem que na interação de díades de irmãos em que um é deficiente mental, a ocorrência de ação negativa é pratica- mente nula, independente da idade dos envolvidos. Além disso, parece haver muitos momentos de ausência de interação entre os irmãos, tanto entre irmãos mais jovens (G1) como mais velhos (G2), para as três atividades desempenhadas. Ademais, a maior diferença que parece ter ocorrido entre os grupos foi para a categoria ajudante, que para G1 ocorreu em maior taxa que para G2.

Então, é possível que irmãos mais jovens assumam com maior freqüência esse papel. Contudo, há que se enfatizar que o grupo de irmãos mais jovens $(\mathrm{G} 1)$ era caracterizado por pré-adolescentes deficientes mentais que apresentavam maiores prejuízos em nível adaptativo, quando comparados aos participantes do G2, o que poderia exigir que os irmãos assumissem mais esse papel. 


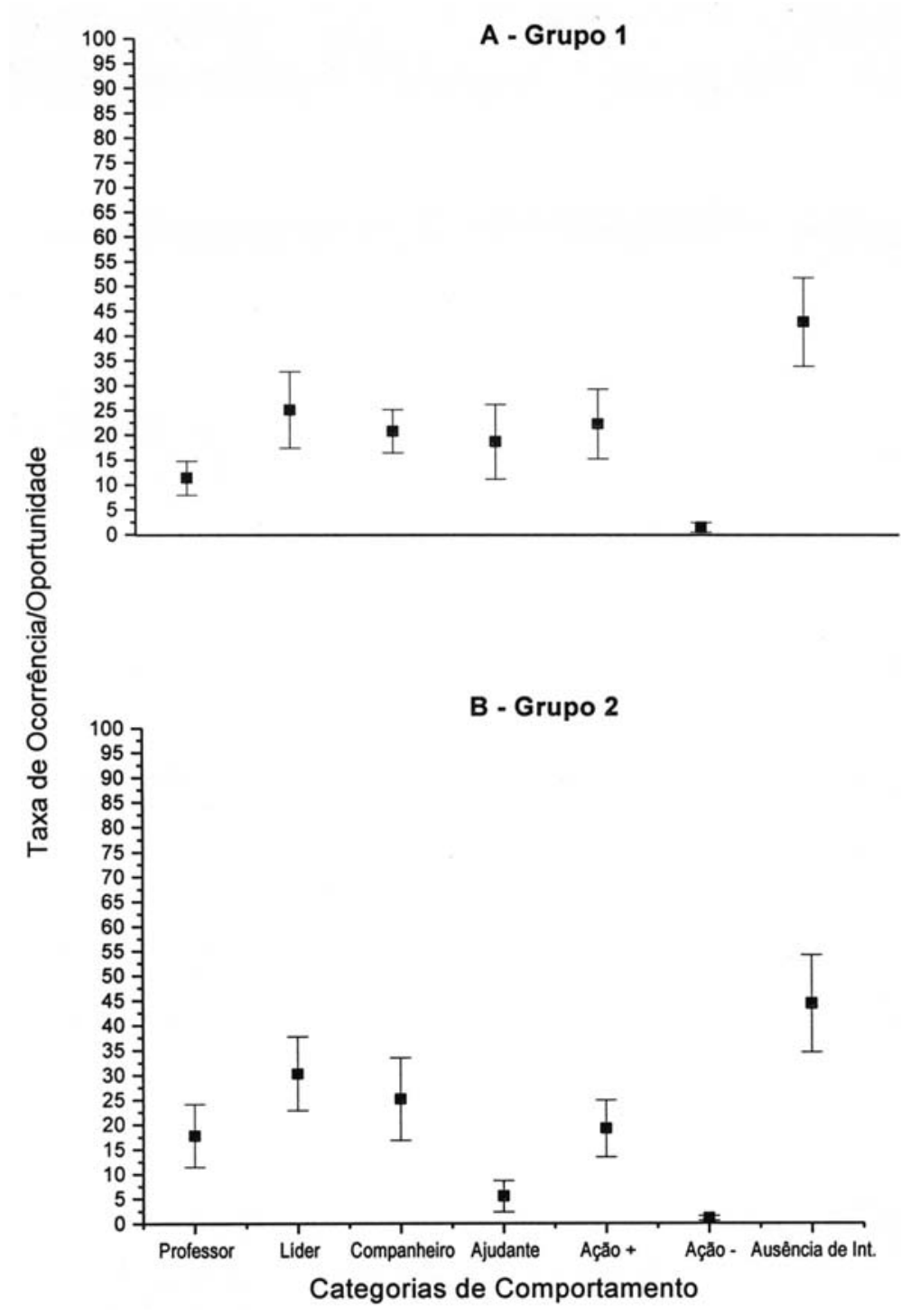

Figuras 2 e 3. Média total da taxa de ocorrência por oportunidade nas três sessões de observação.

\section{Apoio Social}

Em relação ao apoio social, foi observada uma diferença estatisticamente significativa entre os grupos apenas para a Escala de Apoio à Maternidade/Paternidade, de maneira que o G1 obteve uma média estatisticamente inferior ao G2 (0,04, p<0,05), no teste estatístico não-paramétrico de Mann-Whitney.

\section{Discussão}

Os resultados deste estudo sugerem que quando observados em suas interações, os irmãos com desenvolvimento típico não apresentam ações negativas em direção ao irmão com deficiência mental; entretanto, os resultados do relato verbal, obtidos pelo Formulário de Irmãos, indicaram que estas ações ocorrem nas interações entre os irmãos, tanto em G1 como em G2. Tais resultados podem ser indicativos do efeito da presença do observador sobre a interação, já que, conforme afirma Dunn (1983), sempre existe a possibilidade de que esta presença altere o comportamento das crianças.

Já, o resultado das observações de que o papel de ajudante parece ser desempenhado em maior taxa pelos irmãos do G1, apoia os resultados obtidos na Entrevista com Irmãos, de que os participantes mais novos ajudam nos afazeres de cuidado com o irmão mais do que os irmãos do G2. Estes resultados parecem confirmar parcialmente a primeira hipótese do presente estudo. Nesse ínterim, ao considerar esse resultado em relação ao resultado obtido com a Escala de Apoio à Maternidade/Paternidade, que revelou menores índices deste tipo de apoio para G1, é possível conjeturar que como as famílias do G1 recebem menos suporte deste nível, há uma maior demanda de ajuda requerida pelo filho deficiente, que pode ser suprida pelo irmão, que, então, desempenha o papel de ajudante em maior escala que os irmãos dos participantes adultos. Entretanto, este resultado permite especular também que a variável de influência pode ser o nível de defici- 
ência dos irmãos, pois conforme citado anteriormente, três irmãos do G1 apresentam um considerável nível de dependência de outras pessoas, o que pode justificar o maior envolvimento dos irmãos com desenvolvimento típico nas tarefas de cuidado. Contudo, tais resultados, ainda que indicativos de diferenças entre os grupos no que se refere ao nível de apoio social e nas interações entre os irmãos, parecem não ser suficientes para sugerir que a segunda hipótese do presente estudo tenha sido confirmada.

Por outro lado, esse resultado pode ser comentado à luz das considerações realizadas por Pereira-Silva e Dessen (2004), de que o fato de os irmãos de crianças com deficiência mental ajudarem mais do que irmãos de crianças com desenvolvimento típico, sugere que a presença de uma criança deficiente mais velha é um estímulo de cuidado que influencia o comportamento de irmãos e irmãs mais jovens. Somado a isso, pode-se especular, que essa influência poderia ser maior para os irmãos em idade escolar do que para os adultos, representados na amostra analisada no presente estudo pelos irmãos de G1 e G2, respectivamente. Seguindo esta hipótese, é possível conjeturar, por exemplo, que o fato dos irmãos em idade escolar terem um envolvimento maior no cuidado e supervisão do irmão com necessidades especiais comparativamente aos irmãos adultos, pode ocorrer em função dos irmãos jovens estarem sob maior controle do comando de seus cuidadores quanto à tarefa de cuidar destes irmãos.

Assim, a análise geral, integrando os resultados da Entrevista de Irmãos, do Formulário e das observações apoiam as indicações da literatura (Cuskelly, 1999; Rossiter \& Sharpe, 2001), de que observações diretas podem oferecer dados que complementem aqueles gerados pelos métodos de relato de pais ou de auto-relato.

Adicionalmente, os resultados da entrevista sugerem a conclusão de que a falta de conhecimentos acerca da deficiência do irmão é predominante, independente da idade dos participantes. Tais resultados corroboram as afirmações de Gargiulo (2003), de que umas das preocupações enfrentadas por irmãos ou irmãs de indivíduos com algum tipo de necessidade especial refere-se às dúvidas sobre o que causou a deficiência e sobre os motivos que levam os irmãos a se comportarem estranhamente.

Além disso, contrariando as indicações de Hallahan e Kauffman (2000) de que a população investigada pode sofrer prejuízos em termos de relacionamento interpessoal, os participantes declararam, sem exceção, que não consideram difícil dizer aos amigos que têm um irmão deficiente, e quase todos habitualmente recebem amigos em casa. Estes resultados podem ser decorrentes de vários fatores, como o pequeno número de participantes na amostra analisada, a classe social, a cultura. Nesse sentido, estudos futuros poderiam ser conduzidos, considerando tais variáveis na investigação do relacionamento interpessoal de indivíduos irmãos de pessoas com necessidades especiais.

\section{Considerações Finais}

Neste estudo investigou-se a relação entre díades de irmãos nas quais aqueles com desenvolvimento típico são os mais novos. Investigações futuras poderiam incluir também grupos formados por irmãos mais novos e também mais velhos, a fim de analisar se há diferenças na interação quando se considera a ordem de nascimento. Estudos longitudinais também podem ser conduzidos, já que permitem acompanhar as mudanças no processo interacional entre os irmãos de pessoas com necessidades especiais, e quais são os aspectos destas mudanças. Outra sugestão para pesquisas futuras relaciona-se à investigação da interação entre os irmãos, em função do gênero dos mesmos e da severidade da deficiência de um dos membros.

Além da contribuição científica que se pretende oferecer com este trabalho, é importante considerar a contribuição prática do mesmo, à medida que ao se conhecer melhor a dinâmica das interações entre pares ou grupos de irmãos que contam com a presença de um membro com necessidades especiais, é possível entender melhor suas necessidades e, assim, aventar hipóteses acerca de atividades que possam ajudar a melhorar tais interações. Utilizando-se da afirmação de Nunes e Aiello (2004), a fal ta de conhecimentos nessa área talvez justifique a quase inexistência no Brasil de serviços dirigidos aos irmãos, já que por enquanto pouco se conhece sobre suas necessidades e interesses. Contudo, há uma dificuldade em saber se serviços desse tipo receberiam a atenção da população, uma vez que a relação com outros membros da família, além de pai e mãe, como avós e irmãos, e que são importantes para o bom desenvolvimento das inter-relações familiares, e dos próprios indivíduos, geralmente não recebem o merecido destaque. Assim, a partir dos resultados aqui relatados, o principal encaminhamento do presente trabalho é o desenvolvimento de um grupo de apoio a irmãos de indivíduos deficientes, visando o fortalecimento do vínculo neste subsistema familiar.

Uma última ressalva a ser feita é que, considerando o baixo número de participantes, os resultados deste estudo não podem ser generalizados para a população como um todo, e não sugerem relações causais. Além disso, o estudo é limitado pela falta de um grupo controle de irmãos com desenvolvimento típico, o que, mais uma vez, surge como sugestão para investigações futuras.

\section{Referências}

Bonds, D. D., Gondoli, D. M., Sturge-Apple, M. L., \& Salem, L. N. (2002). Parenting stress as a mediator of the relation between parenting support and optimal parenting. Parenting: Science and Practice, 2(4), 409-435.

Cuskelly, M. (1999). Adjustment of siblings of children with a disability: Methodological issues. International Journal for the Advancement of Couselling, 21, 111-124. 
Dunn, J. (1983). Sibling relationships in early childhood. Child Development, 54, 787-811.

Dunst, C. J., Jenkins, V., \& Trivette, C. M. (1994). Measuring social support in families with young children with disabilities. In C. J. Dunst, C. M. Trivette \& A. Deal (Eds.), Supporting and strengthening families: Methods, strategies and practices (pp. 152160). Cambridge, UK: Brookline Books.

Dunst, C. J., Trivette, C. M., \& Cross, A. H. (1986). Mediating influences of social support: Personal, family, and child outcomes. American Journal of Mental Deficiency, 90(4), 403417 .

Dyson, L. L. (1989). Adjustment of siblings of handicapped children: A comparison. Journal of Pediatric Psychology, 14, 215-229.

Frank, N. (2000). Helping families support siblings. In P. J. Beckman (Ed.), Strategies for working with families of young. children with disabilities (pp. 169-188). Baltimore, MD: Paul Brookes.

Gamble, W. C., \& McHale, S. M. (1989). Coping with stress in sibling relationships: A comparison of children with disabled and nondisabled siblings. Journal of Applied Developmental Psychology, 10, 353-373.

Gargiulo, R. M. (2003). Person with autism spectrum disorders. In Special education in contemporary society: An introduction to exceptionality (pp. 513-540). Belmont, CA: Thomson Learning.

Glasberg, B. A. (2000). The development of siblings' understanding of autism spectrum disorders. Journal of Autism and Developmental Disorders, 30(2), 143-156.

Hallahan, D. P., \& Kauffman, J. M. (2000). Parents, families, and exceptionality. In Exceptional learners: Introduction to special education (pp. 126-130). Upper Saddle River, NJ: Allyn and Bacon.

Hastings, R. P. (2003). Behavioral adjustment of siblings of children with autism engaged in applied behavior analysis early intervention programs: The moderating role of social support. Journal of Autism and Developmental Disorders, 33(2), 99-104.

Langford, C. P. H., Bowsher, J., Maloney, J. P., \& Lillis, P. P. (1997). Social support: A conceptual analysis. Journal of Advanced Nursing, 25, 95-100.

Leet, H. E., \& Dunst, C. J. (1994). Measuring the adequacy of resources in households with young children. In C. J. Dunst, C. M. Trivette \& A. Deal (Eds.), Supporting and strengthening families: Methods, strategies and practices (pp. 105-114). Cambridge, MA: Brookline Books.

Lobato, D. (1990). Brothers, sisters, and special needs: Information and activities for helping young siblings of children with chronic illnesses and developmental disabilities. Baltimore, MD: Paul H. Brookes.

Nunes, C. C. (2006). Interação entre irmãos de indivíduos com deficiência mental: O papel da idade e do apoio social da família. Dissertação de Mestrado não-publicada, Programa de Pós-Graduação em Educação Especial, Universidade Federal de São Carlos, SP.

Nunes, C. C., \& Aiello, A. L. R. (2004). O convívio com irmão especial e a caracterização da interação: Um estudo descritivo. Revista Brasileira de Educação Especial, 10(2), 143-160.

Orsmond, G. I., \& Seltzer, M. M. (2000). Brothers and sisters of adults with mental retardation: Gendered nature of the sibling relationship. American Journal on Mental Retardation, 105(6), 486-508.

Pereira-Silva, N. L., \& Dessen, M. A. (2001). Deficiência mental e família: Implicações para o desenvolvimento da criança. Psicologia: Teoria e Pesquisa, 17(2), 133-141.
Pereira-Silva, N. L., \& Dessen, M. A. (2004). O que significa ter uma criança com deficiência mental na família? Educar, 23, 161-183.

Rossiter, L., \& Sharpe, D. (2001). The siblings of individuals with mental retardation: A quantitative integration of the literature. Journal of Child and Family Studies, 10(1), 65-84

Turnbull, A. P., \& Turnbull, H. R. (2001). Families, professionals and exceptionality: Collaboration for empowerment (4th. ed.). Upper Saddle River, NJ: Merrill.

Van Riper, M. (2000). Family variables associated with wellbeing in siblings of children with Down syndrome. Journal of Family Nursing, 6(3), 267-286.

Williams, L. C. A., \& Aiello, A. L. R. (2001). O Inventário Portage Operacionalizado: Intervenção com famílias. São Paulo, SP: Memnon.
Recebido: 11/07/2006 $1^{a}$ revisão: 01/03/2007 Aceite final: 27/06/2007 